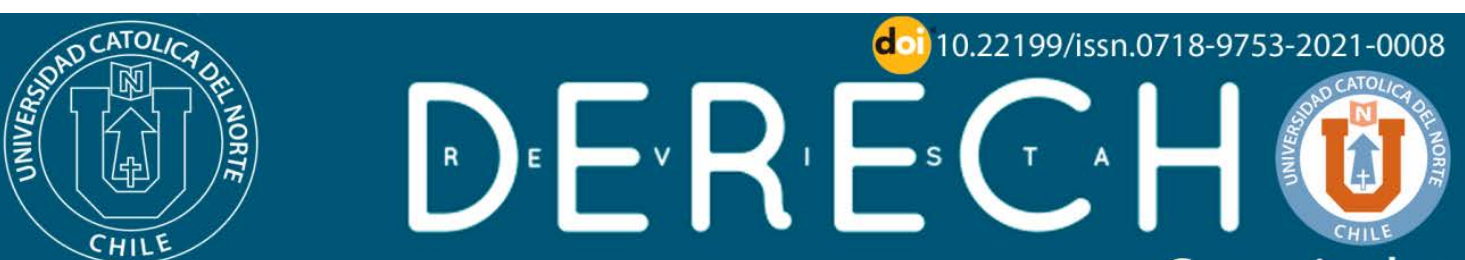

C o qu i m bo

REVISTAS CIENTIIFICAS

ISSN: 0718-9753 (En línea)

\title{
Regreso a una teoría formal del deber jurídico en el ámbito de la omisión impropia
}

\section{Back to the formal theory of legal duty in the context of improper omission}

\section{Luis Emilio Rojas Aguirre1 (D) https://orcid.org/0000-0001-7232-4256}

'Universidad Alberto Hurtado, Santiago, Chile. Profesor de Derecho Penal. Abogado. Doctor en Derecho, U. Freiburg, Alemania.

@lurojas@uahurtado.cl

(cc) BY

\section{Resumen:}

Sobre la base de un planteamiento que postula la necesidad de regresar a una versión reformulada de la antigua teoría formal del deber jurídico, el trabajo aborda la cuestión de si la asunción fáctica y la injerencia pueden constituir una fuente formal en el sentido de dicha teoría. Ya se parte de la premisa, entonces, de que ambos son supuestos diferentes entre sí. Pues, se asume fácticamente una labor de protección o de vigilancia dirigida positivamente a la evitación del resultado. Y la pregunta que se plantea respecto de la asunción es si por esta circunstancia fáctica puede surgir un deber jurídico de evitación del mismo. En cambio, el caso de la injerencia, si bien se parece, es estructuralmente distinto. Porque aquí la acción previa no se encuentra dirigida a la evitación del resultado sino que, al revés, causa el peligro que luego amenaza realizarse en el resultado. Y la cuestión aquí es si de dicha acción previa puede surgir un deber jurídico dirigido positivamente a la evitación del mismo.

Palabras Clave: Obligación jurídica; Asunción fáctica; Injerencia; Conducta pasiva.

\begin{abstract}
:
On the basis of an approach that requires the need to get back to a reformulated version of the old formal legal duty theory, the paper addresses the question of whether "assumption of responsibility" and "the duty to remove a danger" can constitute a formal source in the sense of that theory. From this premise, it follows, that both constitute different cases. Since it is assumed, factually, that there is an activity of protection or surveillance positively directed to prevent the result. The question that arises concerning the assumption of responsibility is whether due to this factual circumstance there is a legal duty to prevent the result. Instead, the duty to remove a danger, albeit similar, is structurally different. In this case the prior action is not directed to prevent the result but, on the contrary, it causes the danger that then threatens to be realized in the result. The question here is whether a legal duty, positively directed to prevent the result, can arise from the prior action.

Keywords: Legal obligation; Assumption; Duty to remove a danger; Passiv conduct
\end{abstract}




\section{Introducción y planteamiento del problema}

Sobre el trasfondo de una extensa revisión histórico-dogmática en el ámbito de la tradición jurídica alemana, se ha intentado mostrar en otro lugar (cfr. Rojas Aguirre, 2018, pp. 690 y ss.) que la formulación originaria del concepto de la posición de garante se explica por un contexto histórico determinado -situado en la década del 30 del siglo pasado-, dentro del cual se insistía -en la misma dirección trazada por el antiguo principio de la actividad previa y frente al criterio sostenido por la jurisprudencia de la época- en la ausencia de causalidad de la omisión y, al mismo tiempo, se temía que la sola exigencia de un deber jurídico fundado formalmente y su infracción, podrían justificar por sí mismas la equivalencia entre omisión y comisión- "comisión por omisión". En ese contexto histórico, la formulación del principio de garantía respondía a la necesidad de dotar de contenido material al deber jurídico formal y permitía, de cierta manera, "compensar" el vacío que se veía en la omisión impropia por la ausencia de causalidad. El concepto de la posición de garante surge así, como una reacción frente a la teoría formal del deber jurídico. Es el producto de un pensamiento orientado materialmente, en una época en la que se tomaba cada vez más distancia de un pensamiento formal comparativamente más orientado a la teoría de las normas y a la idea de accesoriedad del Derecho penal.

En nuestro contexto, es legítimo preguntarse ya por la pertinencia de recurrir a esa tradición jurídica. Sobre el punto, Novoa Monreal (2005) hacía ver, por un lado, que "...la teoría del delito de comisión por omisión pertenece por entero a la doctrina penal" (p. 326), es decir, ha sido elaborada por la doctrina al margen de los conceptos recogidos por la legislación, pues, "el legislador chileno no menciona esta clase de delitos" (Novoa Monreal, 2005, p. 326). Por otro lado, Novoa Monreal (2005) constataba que esa teoría "es obra casi exclusiva de los tratadistas y jurisprudencia alemanes", pero que "su lógica armonía con principios que la ley nacional admite, conduce a que se pueda admitir su aplicación" (p. 326), de modo que, a pesar de su origen foráneo, es aplicable a nuestra legislación penal. Ambas razones son más que suficientes para justificar el estudio de los conceptos desarrollados en el marco de esa tradición jurídica, y partir con ellos. Pero además se ven reforzadas por la circunstancia de que "la teoría de la comisión por omisión" surgió con más de un siglo de antelación a la reforma del Strafgesetzbuch ${ }^{1}$ (StGB, 1871) que introdujo el § 13 a su parte general, de modo tal que la función que vino a cumplir esta regla consistió básicamente en reconocer legislativamente los criterios elaborados al calor de una discusión entre doctrina y jurisprudencia, que se había desarrollado por todo ese tiempo en el seno de esta tradición. En ausencia todavía de una cláusula en la parte general de nuestro Código Penal (1874) que reconozca explícitamente la omisión impropia - de la ausencia de tal cláusula y, al mismo tiempo, partiendo de una serie de premisas, entre otras, (1.) una peculiar teoría de las normas, en la que se funda el

\footnotetext{
${ }^{1}$ Código Penal alemán.
} 
concepto de antinormatividad desarrollado por Kindhäuser (1989, pp. 50 y ss.), (2.) una determinada concepción de la categoría del tipo y, asimismo, (3.) que el Código Penal chileno (1874, art. 1) no acuña un concepto de delito sino que de "hecho punible", Contesse Singh (2017, p. 24 y ss.), concluye que, de acuerdo a las reglas vigentes de nuestro Código Penal (1874) sometido al principio de legalidad, la omisión impropia es un "delito no punible". Llama poderosamente la atención que, partiendo de premisas teóricas radicalmente diversas, se arribe a la misma conclusión a la cual llegaron los finalistas poco antes de ser incorporada la cláusula del $\S 13$ del StGB $(1871)^{2}-$, los conceptos y criterios desarrollados en el marco de esa tradición jurídica por cierto que pueden servir a la aplicación legítima de normas de sanción en tal clase de casos, en la medida en que ayuden a delimitar el ámbito de aplicación de esta forma de realización delictiva, por lo demás reconocida en nuestra jurisprudencia de los tribunales superiores de justicia, aún no bajo esa denominación, a más tardar desde 1917 (Urquieta con Tracción Eléctrica, 1917; cfr. Quintana Román, s. f.).

Ahora bien, en un contexto como el actual, en el que se dispone de una teoría bastante diferenciada de la imputación objetiva y donde al mismo tiempo se ha sometido a revisión el concepto de causalidad, la posición de garantía entendida como una categoría que supone diversos criterios materiales -v.gr.: el "momento de peligro"- para complementar el deber formal y así dotar de contenido material a la omisión impropia, se ha tornado prescindible. En el plano del tipo objetivo de esta clase de omisión, ahora es perfectamente plausible empezar el análisis con (1.) la verificación de la existencia formal del deber jurídico de evitación, seguir con (2.) la comprobación de la causalidad basada en un juicio de probabilidad rayano en la certeza y terminar el análisis con (3.) la observación de los criterios de imputación objetiva v.gr.: riesgo permitido, principio de autorresponsabilidad de la víctima y principio de confianza-. En comparación con un modelo de análisis que confunde la pregunta por la existencia del deber llamado "obligación de garantía", con la exigencia de la generación previa de un "momento de peligro" para el bien jurídico protegido, pareciera que el modelo aquí propuesto, que entonces surge de una reformulación moderna de la teoría formal del deber jurídico, es más diáfano y ordenado.

En nuestro medio, un ejemplo del modelo que confunde ambas preguntas puede extraerse de la formidable obra ya moderna - de fines del siglo 20- de Politoff Lifschitz (1997), quien menciona, en el siguiente orden, seis requisitos para la configuración del delito de omisión impropia. Primero, la producción del resultado típico que la acción omitida pudo evitar. Segundo, también en el ámbito de la tipicidad, “...la exclusión de aquellos resultados que, por derivar de riesgos generales de la vida no jurídicamente desaprobados, no son objetivamente imputables..." (Politoff Lifschitz, 1997, p. 314) -con un sugerente ejemplo-. Tercero, la existencia de "...una situación de riesgo para el bien jurídico evitable casi con certeza ('rayana en la seguri-

\footnotetext{
${ }^{2}$ ver capítulo 1.2. párrafo 2.
} 
dad' [cita de Jescheck]) por una actuación del autor" (Politoff Lifschitz, 1997, p. 314). Cuarto, el deber jurídico especial de protección derivado de la posición de garante del autor "...no son imputables los riesgos ajenos al especial deber de cuidado..." (Politoff Lifschitz, 1997, p. 314). Quinto, en el caso específico, la concurrencia efectiva de la posibilidad real para el sujeto de ejecutar la acción esperada. Sexto, la equivalencia entre omisión y comisión, esto es, “...directamente subsumible en el correspondiente tipo legal" (Luzón Peña, citado en Politoff Lifschitz, 1997, p. 314). De todos estos requisitos, Politoff Lifschitz (1997) trata solo los dos fundamentales de la posición de garante y de la equivalencia con la comisión activa. Respecto de la posición de garante, sostiene que, en nuestro derecho, ella solamente puede surgir de las fuentes formales de la ley y el contrato, rechazando, en consecuencia, el hacer precedente peligroso -injerencia- como fuente. Mas aclara que la fuente legal solamente puede tomarse en cuenta sobre la base de la asunción efectiva de la posición de protección del bien jurídico, por ejemplo, en la relación entre cónyuges:

Si el marido ha cerrado intencionalmente los espacios a que podía acudir la mujer enferma, asumiéndolos enteramente, ha creado una condición para aumentar la situación de peligro, ya que la suerte de ella depende de su actuación y su omisión podrá ser encuadrada eventualmente en el tipo de homicidio doloso o culposo. (Politoff Lifschitz, 1997, p. 319)

En cuanto al otro requisito de la equivalencia entre omisión y comisión activa, advierte que "Un excesivo formalismo pudiera hacer pensar que la combinación de la no actuación de una posibilidad real, junto con la existencia del deber de garante, sería suficiente para imputar el resultado" (Politoff Lifschitz, 1997, p. 322), expresando así el mismo temor que se encuentra en el origen de la formulación del principio de garantía. Pero Politoff Lifschitz (1997) aclara enseguida que ello no es así, pues la omisión solo puede equipararse, por ejemplo, a la "...acción de matar..." (p. 321) cuando el contexto de la situación creado por el autor al asumir la función de garante lo coloca en la "...posición de controlar la posibilidad de conjurar el riesgo" (Politoff Lifschitz, 1997, p. 322), cuestión que ocurriría en el caso del marido que, ante la enfermedad o accidente de la mujer, cierra todas las otras vías de socorro y asume la "...posición exclusiva de protector" (Politoff Lifschitz, 1997, p. 322), dejando la suerte de la víctima entregada a su merced. Es decir, “...cuando la asunción de la posición de garante tiene lugar en circunstancias tales que crean un peligro para el evento de que se omita la acción esperada" (Politoff Lifschitz, 1997, p. 323). Pues, según Politoff Lifschitz (1997), es justamente “...la asunción del deber de garante [...] un factor cofundante del peligro, en cuanto éste se tiene, por ello, por controlado y eventualmente conjurado" (p. 323).

Pues bien, la confusión de requisitos planteados antes por separado, como son la posición de garante y la equivalencia entre omisión y comisión, no solo queda en evidencia en el planteamiento reseñado, sino que parece formularse consciente y explícitamente. Como puede observarse patentemente en el ejemplo del marido y su 
cónyuge, la asunción efectiva de la función de protección que crea o aumenta el peligro para el bien jurídico, es requisito adicional a la existencia formal del deber de garante y, a su vez, esa misma circunstancia "cofundante" del peligro es condición de la equivalencia entre omisión y comisión. Tales circunstancias fácticas dotan de contenido material a la posición de garante $y$, al mismo tiempo, fundan la equivalencia material entre omisión y comisión activa. Respecto de la asunción fáctica como requisito adicional al mero deber, a veces no queda muy claro si con tal exigencia, en rigor, se quiere aludir al presupuesto bastante obvio de que el cumplimiento del deber solo adquiere sentido en el momento en que surge efectivamente una situación de peligro para el bien jurídico protegido. En cambio, si con ella se pretende agregar el requisito de que la asunción efectiva de la función de protección traiga consigo crear o incrementar tal peligro, se incurre en una contradicción en los términos. Pues, asumir efectivamente la protección de un bien jurídico, no puede significar al mismo tiempo conjurar el peligro y crearlo o disminuirlo y aumentarlo. Tendría algo más de sentido desglosar la exigencia de asunción fáctica del deber de garante, por ejemplo, en términos de colocarse en posición efectiva de cumplirlo -no de infringirlo-, como ocurre en el caso del marido. Y, de modo separado, exigir alguna circunstancia fáctica adicional que sea cofundante del peligro, para que luego la omisión sea considerada materialmente equivalente a la comisión activa. Pero, así formulada esta exigencia, además de implicar un frontal regreso al principio de la actividad previa postulado en la segunda mitad del siglo 19 por la doctrina alemana (crítica en Rojas Aguirre, 2018, pp. 695 y ss.), supone erigir el hacer precedente en el sentido de la injerencia como un requisito de tal equivalencia, al mismo tiempo que desconocer su status de fuente del deber de garante. Supone asimismo que la equivalencia postulada es entre omisión y acción, cuando, en rigor, tal equivalencia es valorativa y se exige entre la omisión y la realización del tipo, no de la acción. Pero, además, esta concepción de la equivalencia material olvida que, en definitiva, ésta se supedita a la concurrencia de los otros cuatro requisitos postulados por el propio Politoff Lifschitz (1997) cuales son, el resultado típico, la exclusión de la imputación en casos de riesgo general de la vida, la situación de peligro y la posibilidad real de realización de la acción impeditiva.

En comparación con ese modelo de análisis, pareciera más claro y ordenado empezar el análisis de los requisitos de la omisión impropia con (1.) la verificación del deber jurídico especial fundado formalmente, seguir con (2.) la constatación de la situación de peligro y de la posibilidad real de su evitación mediante la realización hipotética de la acción impeditiva -causalidad, considerar (3.) la aplicación de otros criterios de imputación objetiva concernientes tanto a la infracción de tal deber jurídico, como a la imputación del resultado, y, finalizar con (4.) la verificación del resultado típico, i.e., del exigido por el tipo correspondiente. Este otro modelo de análisis, derivado del planteamiento teórico aquí propuesto, sin embargo, parte de la premisa, por una parte, que la equivalencia postulada es entre la omisión y la realización 
del tipo de injusto de un delito de acción, en este sentido, ya en 1932, Gallas (1989), señala que:

...constatar la antijuridicidad de la realización típica no implica entonces (en tanto nos encontramos en el ámbito del precepto penal concreto) otra cosa que observar materialmente el injusto descrito en el tipo en su contenido inmanente de deber; en esta constatación, no se trata de la verificación de un elemento autónomo del delito junto a la realización típica. (p. 47) $)^{3}$

A su vez, se parte de la premisa surgida recién con el desarrollo posterior de la teoría de la imputación objetiva, cuya aplicación en este ámbito implica que, para la configuración del injusto típico, se exige, además de la causalidad, la contravención de una norma de comportamiento, que en el caso de la omisión adquiere la forma de un mandato o requerimiento de realizar la acción impeditiva, y, en los delitos de resultado, la imputación de éste a la omisión típica. Asimismo, se parte de la base que el concepto de delito acuñado por el Código Penal chileno (1874, art. 1) incluye en su campo semántico a la omisión después tildada de "impropia", de manera que esta regla funge como un reconocimiento implícito pero formal de este modo de realización delictiva (recientemente, en esta dirección; Wilenmann von Bernath, 2016, p. 300 y ss.). En virtud de esta serie de premisas, el modelo de análisis propuesto aquí es, de lege lata, plenamente aplicable a los casos en que, en nuestra tradición jurídica, viene en consideración la responsabilidad por "omisión impropia".

A continuación, se ofrece una síntesis del planteamiento teórico que subyace al modelo de análisis propuesto. Este discurre sobre la base de un regreso a la teoría formal del deber jurídico, regreso que implica, como se ha visto, postular la necesidad de verificar, como primer paso en el análisis, la existencia formal de un deber jurídico especial. Implica, al mismo tiempo, que una vez constatada la existencia de tal clase de deber jurídico, no es menester adicionalmente verificar la "asunción fáctica" de tal función, sin perjuicio de exigirse la concurrencia de una situación de peligro y de la posibilidad efectiva del cumplimiento del deber, como presupuestos de su infracción. Pero ese planteamiento también conlleva poner en cuestión la asunción fáctica como fuente del deber de garante, por la simple razón de que un deber jurídico surge de una fuente formal ${ }^{4}$-. Por otra parte, el postulado regreso a una teoría formal del deber jurídico se ve confrontado con la necesidad de reconducir la injerencia al presupuesto común, cual es la exigencia de una fuente formal del deber. Partiendo de una diferenciación ya en un plano descriptivo entre el supuesto de la "asunción fáctica" y el del "hacer precedente", en el sentido de la injerencia, se plantea que ésta, en la medida en que sucede con infracción de la norma de comportamiento subyacente al tipo de la ley penal, funge como fuente del deber jurídico de evitación junto

\footnotetext{
${ }^{3}$ Todas las traducciones fueron realizadas por el autor del artículo.

${ }^{4}$ Ver capítulo 2
} 
a la ley y el contrato ${ }^{5}$. Suscribe esta tripartición de las fuentes del deber jurídico Novoa Monreal (2005, p. 326 y s.)

\section{Síntesis previa del planteamiento teórico}

\subsection{El deber jurídico especial como requisito básico}

Si el tipo de injusto de un delito de resultado se compone de causalidad y de imputación objetiva, como se suele entender actualmente, entonces la configuración de una omisión impropia presupone la existencia formal de un deber jurídico especial. Tanto la comprobación del nexo de causalidad como luego la aplicación de criterios de imputación objetiva, como por ejemplo, el principio de autorresponsabilidad de la víctima, el principio de confianza o el riesgo permitido, presuponen en este ámbito la existencia de tal deber.

Para la verificación del nexo de causalidad, es preciso formular un juicio de probabilidad acerca de lo que habría sucedido en el evento hipotético de que el sujeto hubiese realizado la acción impeditiva ordenada. Colocado en ese escenario hipotético, resulta muy difícil saber si esto habría ocurrido sin representarse la acción impeditiva que el sujeto concretamente debía realizar. La acción impeditiva concreta que se agrega hipotéticamente, difícilmente puede pensarse sin considerar el alcance del deber, de ahí que en el ámbito del delito impropio de omisión no pueda separarse la comprobación de la causalidad de la aplicación del criterio de la conducta alternativa hipotética conforme a deber, al respecto Freund (2017); la pregunta que resta en pie, y que por sí misma justifica una investigación de mayor alcance, es si tal separación se justifica todavía en el ámbito del delito de acción, al respecto Puppe (2015), quien tacha de un error la separación trazada por Honig (p. 208) entre causalidad e imputación objetiva, al mismo tiempo que sugiere la necesidad de un regreso al concepto de causalidad adecuada en el sentido de von Kries (Puppe, 2015, p. 213, nota 49). Frente a la misma situación fáctica de peligro, por ejemplo, una enfermedad grave de un niño, lo que debe hacer el médico es distinto que el deber de acción de sus padres o cuidadores.

Por su parte, la aplicación de criterios de imputación objetiva en el ámbito del delito de omisión necesita fijar un punto de partida en el deber jurídico del sujeto. Por cierto, y esto ya era bastante claro en la formulación originaria de la teoría formal del deber jurídico (cfr. Rojas Aguirre, 2018, pp. 694 y 695), la sola infracción del deber jurídico no fundamenta aún la equivalencia entre omisión y comisión. Es necesario ahora observar la pertinencia de aplicar alguno de los criterios de imputación objetiva.

\footnotetext{
${ }^{5}$ Ver capítulo 3
} 
Por ejemplo, el Código Civil (2000, art. 102) establece, entre otros, un deber de auxilio mutuo entre los cónyuges -y lo mismo hace la Ley $\mathrm{N}^{\circ} 20.830^{6}$ (2015, art. 14)-. En el caso concreto de una situación de peligro, a pesar de la existencia formal del deber, el principio de autorresponsabilidad de la víctima impediría afirmar la configuración ya de una infracción a tal deber, en la medida en que la decisión del cónyuge o conviviente civil expuesto al peligro pueda calificarse como ejercicio de su derecho a la autodeterminación -o, con otras palabras-, se podría hablar de un incumplimiento del deber de auxilio mutuo para efectos jurídico-civiles, mas no de equivalencia entre omisión y comisión para efectos penales.

Justamente, la función que cumplen los criterios de imputación objetiva reside en que permiten observar el fundamento material común de la responsabilidad penal, tanto por acción como por omisión. Así, por ejemplo, si resulta pertinente la aplicación del principio de confianza, significa que, en el caso concreto, la situación de peligro para el bien jurídico se enmarca todavía en el espacio de la confianza legítima, y si bien existe formalmente un deber jurídico, en definitiva no se justifica materialmente la restricción de la libertad del sujeto obligado.

Es aquí donde cobra vigencia el juicio de ponderación entre bien jurídico y ámbito de libertad del sujeto, que ya Mayer (1934, p. 76 y ss.) creía necesario para el juicio de equivalencia entre omisión y comisión. Sólo que en esa época, en ausencia todavía de una teoría de la imputación objetiva, tal criterio de orden material fundaba la posición de garantía misma del sujeto para efectos de su responsabilidad por omisión. Un desarrollo diferenciado de la teoría de la imputación objetiva que, por ejemplo, distingue, por un lado, la pregunta por la legitimación de la restricción de la libertad de acción del ciudadano -cuestión que atañe al fundamento de la norma de conducta- $y$, por el otro, criterios adicionales de legitimación para la aplicación de la norma de sanción (en este sentido, Frisch, 2012, p. 71 y ss.), ubicaría sistemáticamente dicho juicio de ponderación a propósito de la pregunta básica por la legitimación de la norma de conducta. En la medida en que la aplicación de dicho criterio material atañe a esta cuestión fundamental de legitimación, sistemáticamente deja de tematizarse en el marco de la pregunta previa sobre la configuración de la posición de garante. En este sentido, el desarrollo ulterior y diferenciado de la teoría de la imputación objetiva, ha vuelto prescindible el concepto de posición de garante en tanto fórmula resumida de los criterios materiales que fundan el mentado juicio de equivalencia entre acción y omisión. Este es el planteamiento central de Freund (1992), es decir, en su función de señalar los elementos, circunstancias y exigencias normativas que deben concurrir para la equivalencia, la posición de garante misma no puede ser un elemento parcial del tipo; no obstante, en el lugar de la posición de garante, acuña la categoría de "responsabilidad especial", bajo la cual entiende una "relación especial" del destinatario potencial de la norma de conducta con el curso dañoso a evi-

\footnotetext{
${ }^{6}$ Que crea el acuerdo de Unión Civil.
} 
tar (Freund, 1992, p. 68 y ss.); esta responsabilidad especial puede derivar, por una parte, de una relación con el origen del peligro -las así llamadas posiciones de garante de una fuente de peligro- (Freund, 1992, p. 159 y ss.) o, de otra parte, de la competencia por el "lugar de destino" del peligro -las así llamadas posiciones de garante de protección- (Freund, 1992, p. 265 y ss.); sin embargo, no es posible determinar la existencia de tal relación del sujeto con el "origen del peligro" o con el "lugar de destino" del mismo, sin recurrir a la existencia formal del deber jurídico, deber que, entonces, se torna precisamente en el criterio que permite diferenciar la responsabilidad general -que subyace, por ejemplo, al tipo de omisión de socorro- de la especial en el sentido de Freund (1992).

La existencia formal de un deber jurídico especial de evitación, constituye un requisito básico de la responsabilidad por omisión impropia. La configuración de esta clase de responsabilidad penal exige, empero, además de la infracción de tal deber, la verificación de un nexo de causalidad y la consideración de otros criterios de imputación objetiva. Pero, en una sociedad como la moderna, donde prácticamente todos los ámbitos de la vida se encuentran regulados jurídicamente, ya no resulta plausible pretender fundar responsabilidad jurídico-penal por omisión en base solamente a elementos fácticos y criterios materiales, como por ejemplo la generación de un "momento de peligro", recurren a éste criterio para fundar la posición de garante: Gallas (1989); Stree (1966, p. 153 y ss.); Blei (1966, p. 122 y ss., 138 y ss.); Seelmann (1989, p. 253); y, Gimbernat Ordeig (2013).

Aunque suene paradójico, aquí radica la intuición correcta de von Feuerbach $(1847, \S 24)$ al formular la versión originaria de la teoría del deber jurídico, que exigía la concurrencia de un fundamento jurídico especial para el castigo de la omisión. En su reformulación moderna, genera certeza jurídica al introducir un filtro con el requisito de la existencia formal de un deber jurídico de evitación. Como ya lo había aclarado Traeger (1913, p. 79), para estar en presencia de tal deber no es suficiente un deber general de auxilio -como el que subyace al tipo de omisión de socorro o al de omisión de denuncia de un crimen próximo a cometerse. Es necesaria la existencia de un deber jurídico especial. Tal deber existe cuando el titular del bien jurídico amenazado tiene correlativamente el derecho a exigir de una persona determinada la evitación del peligro - derecho cuya existencia precisamente se cuestiona en la situación fáctica de la omisión de socorro o de la omisión de denuncia (pregunta que se encuentra detrás del cuestionamiento a la legitimación de tipos basados en el principio de solidaridad, por ejemplo; Morgenstern, 1997). En un ordenamiento jurídico positivo, los derechos y las obligaciones correlativas surgen exclusivamente de la ley o de un contrato. Este es el postulado central de la teoría formal del deber jurídico en su formulación moderna.

De acuerdo a este razonamiento, entonces, la diferencia entre un deber jurídico especial y el deber general de auxilio, reside en la existencia de tal plexo de dere- 
chos y obligaciones correlativas. Esta diferencia no puede ser introducida por la propia ley penal cuya aplicación se ventila en el caso concreto, sin exponerse a una tautología. La ley penal positiviza el deber jurídico de evitación en la forma negativa de una prohibición o positiva de un mandato, con el fin de proteger el bien jurídico correspondiente -fin de protección de la norma-. Pero, es la existencia de un deber jurídico especial la que vuelve obvia la transformación de una prohibición en un mandato, cuyo incumplimiento constituye el presupuesto fundamental de la responsabilidad por omisión impropia. Dicho de otro modo, y si se parte de la distinción entre una norma primaria de conducta y una norma secundaria de sanción (acerca de las raíces de esa distinción, Renzikowski, 2002, p. 3 y ss.), tal deber jurídico vuelve operativa la norma de comportamiento en la forma de un mandato, cuya infracción mediante omisión constituye un presupuesto básico de la aplicación legítima de la correspondiente norma de sanción penal.

Ese deber jurídico surge, en consecuencia, de una ley distinta que la penal, esto es, de una ley extrapenal -o pre-penal-, por ejemplo, de Derecho civil o de Derecho administrativo. Sin embargo, no puede tratarse de cualquier ley extrapenal, sino que de una pertinente al caso. $Y$ es pertinente si la norma jurídica pre-penal incluye dentro de sus fines la protección del mismo interés jurídico resguardado por la norma de comportamiento jurídico-penal, cuya aplicación se ventila en el caso concreto. Más precisamente, el mismo bien jurídico protegido por la norma de conducta cuya infracción es exigida para la aplicación legítima de la correspondiente norma de sanción penal. No cabe exigir que sea su fin exclusivo, pues regularmente tales normas jurídicas pre-penales cumplen una función configuradora, que supera con creces el acotado fin de la no lesión a un bien jurídico. Regulan y configuran positivamente múltiples intereses jurídicos. En este sentido, basta que exista consistencia entre el fin de protección de la norma jurídica extrapenal y el de la norma de comportamiento jurídico-penal.

Por otra parte, tampoco es requisito que el fin de protección se encuentre formulado explícitamente en el texto de la norma jurídica pre-penal. Sería bastante absurdo exigir que, por ejemplo, el art. 222 inciso $2^{\circ}$ del Código civil dijera expresamente que "los padres deben evitar la muerte de sus hijos", o que el art. 102 del mismo código declarase que "los cónyuges deben procurarse recíprocamente evitar una enfermedad grave". La norma jurídica extrapenal podría decirlo así, pero no es requisito que lo haga. La operación determinante, como ya la practicaba el Reichsgericht en su jurisprudencia de principios del siglo 20 (Unfallrente. Betrug durch Verschweigen der Heilung, 1913, p. 415 ; Abtreibungsversuch. Beihilfe, 1921, p. 169; y, Brandstiftung durch Unterlssfung, 1930, p. 273), consiste en extraer el deber jurídico especial a partir de una fuente formal. En un sentido similar, Freund (1992, p. 33 y ss.), mantiene la exigencia de un deber jurídico como un elemento imprescindible de una adecuada teoría de la equivalencia, pero advierte que aquélla no debe entenderse en un sentido positivista, sino que lo determinante es el contenido material del orde- 
namiento jurídicamente relevante de conducta, es decir, en el ámbito pre-jurídico penal interesa solamente si dicho ordenamiento significa una solución adecuada al conflicto entre libertad de acción e intereses en la conversación de bienes; luego, al analizar la categoría de la responsabilidad especial, en su modelo de responsabilidad común por acción y omisión (impropia) basado en dos pilares -"utilidad del seguimiento de la norma" y "responsabilidad especial"-, el deber jurídico extraído formalmente parece cumplir una función indiciaria, así, por ejemplo, los deberes jurídico civiles de aseguramiento en el tráfico constituyen una sub-exigencia del deber de evitación de peligros, p. 166 y ss.; algo similar ocurre con los "deberes de protección", ámbito en el cual Freund (1992, pp. 265 y ss.) no ve una diferencia fundamental con los deberes de evitación de peligros.

Lo dicho precedentemente, vale también respecto del contrato como fuente de un deber jurídico especial (de otra opinión, Traeger, 1913, p. 82 y ss.). La función del contrato radica precisamente en crear derechos y obligaciones correlativas entre las partes. En este sentido, su existencia introduce una diferencia con el deber general de auxilio. Para este efecto, debe reunir la misma exigencia de pertinencia que atiende al fin de protección de la norma. Al igual que la ley extrapenal, acá tampoco es requisito que tal fin sea exclusivo -regularmente no lo será- ni que sea explícito. También sería absurdo exigir que, por ejemplo, el contrato de un médico con su paciente diga explícitamente que aquél hará lo posible para evitar la muerte de éste.

\subsection{Clasificación del deber jurídico especial}

Más allá de la ley y del contrato, como ya lo intuyera el propio von Feuerbach (1847), no existen fuentes del deber jurídico especial. Así resuelve la teoría formal del deber jurídico la cuestión de las fuentes posibles del mismo. Sin embargo, su formulación todavía es ciega frente al contenido y alcance del deber jurídico especial. Una clasificación del deber jurídico a partir de su contenido, sólo fue posible de la mano de un pensamiento orientado materialmente, tal como fuera planteado, por ejemplo, por Mayer (1934, p. 81 y ss.), que distingue dos clases de posiciones especiales del sujeto, derivada una, de la relación del mismo con el peligro, y la otra, de la relación del sujeto con el titular del bien jurídico. De esta manera, se adelanta a la formulación ulterior de la así llamada teoría de las funciones.

Si por teoría de las funciones se entiende una clasificación de las posiciones de garante como elemento del tipo del delito de omisión impropia, pues bien, tal teoría no se formula en la obra de Kaufmann (1959), quien parte de la premisa de que solamente una acción final puede ser objeto de una norma (Kaufmann, 1959, p. 2 y ss.); al mismo tiempo, en el plano óntico, sostiene que si bien puede hablarse de causalidad entre la acción omitida y la ocurrencia o no de un acontecimiento, no puede afirmarse lo mismo entre el sujeto y la acción omitida (Kaufmann, 1959, p. 60 y ss.); si bien la omisión supone la capacidad de una dirección final, ella misma no se somete 
a tal dirección (Kaufmann, 1959, p. 74 y ss.); existe una diferencia fundamental entre acción y omisión, pues, si bien la capacidad de acción es común a ambas, falta en ésta el dolo entendido como voluntad de realización, el poder fáctico final sólo se refiere a la acción omitida (pp. 81 y ss.); esa diferencia atañe a la estructura misma de la omisión -es decir: esta tiene una estructura inversa a la acción, de ahí la formulación del principio de inversión, según el cual la misma consecuencia jurídica se presenta cuando concurre respecto de la acción omitida la estructura inversa que en el delito de acción -por ejemplo, punibilidad no de la "tentativa de omisión", sino que de la omisión del intento de realizar la acción ordenada a pesar de la capacidad de acción-, lo que implica que no puede hablarse de "comisión mediante omisión", sino que de omisión de la acción debida a pesar de la capacidad de acción (Kaufmann, 1959, p. 85 y ss.); esa estructura invertida se presenta en el delito propio de omisión (Kaufmann, 1959, p. 91 y ss.), donde el autor ya sostiene que el deber no pertenece a ningún elemento en la estructura del delito, pues el tipo se orienta a la norma (Kaufmann, 1959, p. 132 y s.); respecto de los delitos impropios de omisión, sostiene que toda su construcción dogmática se orienta al "fin político-jurídico" de igualar el marco penal con el delito de acción (Kaufmann, 1959, p. 239 y ss.); respecto de la concepción de Nagler (1938, p. 51 y ss.), en cuanto a la posición de garante como elemento no escrito del tipo, la rechaza y sostiene que es una exigencia del delito impropio de omisión que no realiza ningún tipo del delito de acción, sino que el tipo (inexistente) del delito impropio de omisión, pues solamente una acción puede contravenir una prohibición, en cambio, una omisión no puede infringir una norma de prohibición (Kaufmann, 1959, p. 249 y ss.); el mandato de evitación del resultado es una norma sui generis, ergo, el delito impropio de omisión se subsume bajo un tipo especial no escrito (Kaufmann, 1959, p. 259 y ss.; es decir, inexistente por el principio de legalidad en su dimensión de lex scripta); el incumplimiento del mandato de evitación del resultado, no se subsume jamás bajo el correspondiente tipo de prohibición, pues la omisión no es un caso especial del delito de acción, sino que un caso genuino del delito de omisión (Kaufmann, 1959, p. 275 y ss.); el delito impropio de omisión exige además una relación cercana del sujeto del deber con el objeto, pero que significa un incremento cuantitativo del contenido de injusto del delito propio de omisión, por lo que no existe una diferencia dogmática entre ambos, sino que sólo en el plano axiológico (Kaufmann, 1959, p. 276 y ss.); se trata de un delito sui generis según tipo, injusto y culpabilidad, ninguna solución dogmática puede colmar el vacío legal, pues el tipo de omisión impropia no solamente es abierto, sino que completamente abierto y no escrito (Kaufmann, 1959, p. 281 y ss.); es en este contexto, esto es, luego de negarle a la posición de garante su status de un elemento no escrito del tipo del delito de acción, donde Kaufmann (1959, p. 283 y ss.) distingue los mandatos de garante, según su objeto, entre la función de protección y la vigilancia de una determinada fuente de peligro, para enseguida acudir al orden de las reflexiones axiológicas, dentro del cual se encuentra la pregunta por la relación de garantía; no existe una diferencia dogmática entre delito propio e impropio de omisión, sino que 
sólo una necesidad político criminal de someterlo al marco penal del delito de comisión (Kaufmann, 1959, p. 304); el deber de garante no es ni un elemento del tipo ni un momento de antijuridicidad, no aparece en ninguna sede de la estructura del delito (Kaufmann, 1959, p. 308). Unos años después, Schöne, (1974), extraería la consecuencia de este planteamiento: luego de analizar las diferentes figuras de omisión repartidas en los tipos de la parte especial -delitos propios de omisión, tipos que contemplan la omisión como alternativa típica a la acción y tipos de omisión tras una descripción activa de la conducta, arriba a la conclusión que la omisión impropia, según el Derecho vigente en esa época justo antes de la introducción de una cláusula de equivalencia en la parte general, se encuentra al margen del texto legal, por lo que la madre que deja de amamantar a su hijo recién nacido responde sólo por una omisión de socorro -StGB (1871, § 330 c), pues la búsqueda de satisfacer necesidades político criminales mediante su castigo a título de omisión impropia contraviene el principio de legalidad consagrado en la Constitución (2005, art. 103, inc. 2).

Como es sabido, dicha teoría clasifica las posiciones de garante entre las que se basan en una función de vigilancia de una fuente de peligro determinada, y las que consisten en una función de protección a un sujeto determinado. La clasificación entre posiciones de garante de vigilancia y de protección, empero, y por mucho que se trate de reconducirla a circunstancias fácticas y criterios materiales (así, por ejemplo, Schünemann, 2009; lo sigue Roxin, 2003), depende, en última instancia, de la clase de deberes que el ordenamiento jurídico positivo impone al sujeto en relación a una fuente de peligro o a otro sujeto. Si este establece deberes jurídicos de aseguramiento, en el sentido de que obligan a organizar de tal manera la fuente de peligro que de ésta no deriven cursos lesivos para terceros, se habla de una posición de garante de vigilancia. Grünewald (2001), critica la extracción, en particular, de los deberes del tráfico desde el Derecho civil para fundar deberes de garante en el Derecho penal, entre otras razones por la ampliación que esos deberes han experimentado para fundar responsabilidad civil en casos que, de acuerdo a los criterios tradicionales de la responsabilidad penal, sería incompatible; tales deberes son concebidos por la jurisprudencia alemana como una cláusula general que suma indeterminación a la regla ya poco taxativa del StGB $(1871, \S 13)^{7}$; en efecto, y como reporta von Bar (1988, p. 169 y ss.), el tradicional "deber general de aseguramiento" se ha ampliado a los "deberes del tráfico" exigiendo sólo un peligro incrementado y considerando otros criterios como las expectativas de confianza; frente a esta tendencia expansiva, sin embargo, Grünewald (2001, p. 133 y ss.), exige para la responsabilidad penal, fiel a un concepto negativo de Derecho (en el sentido de Hegel, 1970), una acción previa que o bien genera un peligro o implica asumir una responsabilidad por una fuente de peligro, junto con la consideración de la legítima confianza surgida de tal asunción. Efectivamente, el problema reseñado existe, pero es importante recordar que

\footnotetext{
${ }^{7}$ Que establece la exigencia copulativa, para la comisión por omisión, de un deber jurídico de evitación y la equivalencia de su incumplimiento con la realización del tipo legal correspondiente.
} 
ya en la extracción del deber jurídico desde una fuente del Derecho civil se aplica un criterio de selección, a partir del fin de protección de la norma de comportamiento jurídico-penal respectiva; luego, el deber jurídico así fundado, se observa desde la perspectiva de los criterios materiales de imputación objetiva, sin que exista ninguna necesidad de extrapolar los criterios de imputación tendencialmente más laxos de la responsabilidad civil por daños; crítico también frente a la tendencia expansiva que implica la accesoriedad al Derecho privado para los efectos de fundar deberes de garante, Seelmann (1994, p. 88 y ss.), frente a la cual propone recurrir a los criterios tradicionales de imputación jurídico-penal que, en el ámbito del delito de omisión, se traduce en "la exigencia de concebir la omisión jurídico-penalmente relevante sólo como la no inhibición de cursos causales propios" (Seelmann, 1994, p. 94 y ss.), exigencia que rige del mismo modo tanto respecto de los deberes de aseguramiento como de los deberes de protección: "en los dos casos, el obligado debe haber puesto por sí mismo mediante su conducta previa la causa para la posterior lesión" (Seelmann, 1994, p. 96).

$\mathrm{Si}$, en cambio, el mismo ordenamiento jurídico impone deberes de protección de un sujeto determinado, se habla de una posición de garante de protección. Dicha teoría no hace más que transponer en el lenguaje de las funciones los deberes jurídicos de aseguramiento, por un lado, y los deberes jurídicos de protección, por el otro. En este sentido, la función de vigilancia es una expresión sintética de los deberes jurídicos de aseguramiento, mientras que la función de protección es una fórmula resumida de esta segunda clase de deberes jurídicos. Aquí radica el límite y al mismo tiempo la virtud de la teoría de las funciones, esto es, en ofrecer un criterio de clasificación de los deberes jurídicos especiales, no a partir de sus fuentes, sino que a la luz del contenido y alcance del deber.

En fin, y tras el desarrollo de la teoría de la imputación objetiva, la categoría de la posición de garante, entendida como una serie de criterios materiales sumada al deber jurídico especial de evitación, se ha tornado prescindible. La aplicación de los criterios de imputación objetiva, empero, supone la existencia formal de un deber jurídico especial. Este deber puede emanar de una ley extrapenal o de un contrato. Desde el punto de vista de su contenido y alcance, puede clasificarse en deberes jurídicos de aseguramiento de una fuente de peligro determinada, y en deberes jurídicos de protección a un sujeto determinado.

La existencia formal de un deber jurídico especial, sin embargo, constituye solamente un requisito básico, por lo que su incumplimiento no funda aún el juicio de equivalencia entre omisión y comisión. Para la formulación de tal juicio, además del nexo de causalidad, es necesario considerar los demás criterios de imputación objetiva, si su aplicación es pertinente en el caso concreto. En definitiva, son estos criterios materiales, y no la existencia formal de un deber jurídico especial, los determinantes para fundar el mentado juicio de equivalencia. Pues, la formulación de este 
juicio supone la concurrencia de los mismos elementos y criterios que legitiman la aplicación de la norma de sanción, contemplada para el correspondiente delito de acción. En este sentido Freund (1992), de ahí que éste hable de "delitos de omisión equivalentes a la comisión" (begehungsgleiche Unterlassungsdelikte) en vez de delitos impropios de omisión.

Estos criterios materiales de imputación objetiva, empero, no pueden sustituir la eventual falta de un deber jurídico especial fundado formalmente en el caso concreto. Desde un punto de vista metodológico, es necesario diferenciar claramente entre la pregunta por la existencia formal de un deber jurídico especial, por una parte, y la consideración de los criterios de imputación objetiva, por otra. Asimismo, y según la versión de la teoría de la imputación objetiva que se siga, cabe distinguir adicionalmente entre criterios, por un lado, que dicen relación con la infracción del deber jurídico especial y, por ende, se sitúan en el plano del comportamiento típico, como por ejemplo el riesgo permitido, el principio de autorresponsabilidad de la víctima y el principio de confianza, y, por otro lado, que atañen a la imputación del resultado, v.gr.: la conducta alternativa hipotética conforme al mismo deber jurídico.

El planteamiento expuesto, que entonces postula el regreso a una teoría formal del deber jurídico, pero enriquecido con los criterios desarrollados posteriormente por la teoría de la imputación objetiva, coloca al menos dos problemas pendientes de análisis. La primera cuestión atañe a la consecuencia de esta tesis respecto de la asunción fáctica de una labor de vigilancia o protección. Pues, si se exige la existencia formal de un deber jurídico, la mera circunstancia de que un sujeto asume tal labor no sería suficiente para fundar la "obligación de garantía". La segunda pregunta, dice relación con la compatibilidad de la injerencia con este postulado regreso. Esta supone, abordar la tautología que implicaría derivar el deber jurídico especial de la circunstancia que el sujeto causó la situación de peligro para el bien jurídico protegido por la norma respectiva.

\section{La asunción fáctica como criterio material: ¿autovinculación sin contrato?}

El postulado regreso a la teoría formal del deber jurídico implica poner en cuestión una premisa de la cual parte la doctrina moderna ampliamente mayoritaria, cual es que, en el fondo, la posición de garante surge de la asunción fáctica de una labor de vigilancia o de protección, mas no de una fuente formal. La cuestión que se plantea bajo ese prisma es si tal deber puede derivar del hecho de asumir una función de vigilancia o de protección. 


\subsection{Premisa de lógica deóntica}

En contra de esta posibilidad, cabe invocar la premisa de lógica deóntica según la cual un imperativo no puede derivar de un conjunto de premisas formado únicamente por descripciones fácticas. Sin perjuicio de su vigencia, Hare (1972, pp. 50 y ss.), el filósofo anglosajón, ha reformulado dicha premisa en los términos siguientes. De acuerdo a su reformulación, no es posible deducir un imperativo de un conjunto de premisas que no contenga al menos un imperativo ${ }^{8}$. Por consiguiente, $y$ para los efectos de la cuestión que nos ocupa, sí sería posible colegir un deber de un conjunto de premisas formado tanto por descripciones fácticas como por al menos un elemento normativo.

Ahora bien, la siguiente pregunta atañe a la clase de elementos normativos que puede satisfacer dicha condición. En el ámbito de la filosofía general, esta cuestión se ha abordado a propósito del acto de habla de la promesa. Así, von Wright (1979, p. 120 y ss.) el filósofo de origen finés, advierte que la sola circunstancia fáctica de que alguien exprese una oración de promesa, no implica que se haya dado una promesa. Por ejemplo, si un niño pequeño dice prometer la entrega de cien marcos el día de mañana, no implica ninguna promesa. Junto a la expresión de la promesa, es necesaria la concurrencia de otros factores para que ese acto de habla constituya una promesa. Si la expresión de una promesa constituye un acto de promesa, entonces existe por un período de tiempo, una determinada relación entre el sujeto que dio la promesa y aquel a quien se la dio. Esta relación es de carácter normativo (von Wright, 1979, p. 114 y ss.) $)^{9}$. Por su parte, Searle (1983, p. 88 y ss.) ha enunciado una serie de condiciones que debe concurrir para que un acto de habla ilocucionario constituya una promesa que efectivamente obliga a quien lo emite en su relación con el oyente, en total son nueve condiciones; entre ellas destaca la condición esencial de la asunción del deber de realizar una acción determinada (Searle, 1983, p. 93).

Estas consideraciones filosóficas se formulan con una pretensión mayor, cual es la de explicar las condiciones bajo las cuales, en una sociedad, una promesa obliga. Por cierto, estas condiciones incluyen a las reglas jurídicas, pero no se agotan en ellas. La cuestión que surge ahora es si la concurrencia de esas condiciones es suficiente para generar una obligación jurídica. Y, más aún, una obligación jurídica cuyo incumplimiento pueda fundar responsabilidad penal (en este sentido; Pawlik, 1999, p. 140 y ss., aunque restringido al ámbito del tipo de estafa). La pregunta, entonces, es si el acto seriamente emitido de prometerle ayuda a otro, genera por sí mismo tal clase de obligación jurídica. En general, la doctrina discute esta cuestión bajo la categoría de la asunción fáctica de una labor de vigilancia o de protección, en cuyo mar-

\footnotetext{
${ }^{8}$ Esta reformulación la propone con el fin de abordar la cuestión del imperativo hipotético.

${ }^{9}$ Esta explicación de la promesa viene precedida de una inversión de la referida premisa de lógica deóntica, según la cual el deber implica el ser -éste se deduce de aquél, pues un deber presupone la capacidad fáctica de su cumplimiento.
} 
co no se satisface con la mera asunción. Exige otras circunstancias fácticas adicionales.

\section{2. ¿La asunción como fuente y como posición de garante a la vez?}

Así, por ejemplo, Stree (1966, p. 150 y ss.) parte de una crítica a la teoría formal del deber jurídico, entre otras razones, porque un mero incumplimiento contractual no puede confundirse con un injusto penalmente relevante. Por otro lado, recurre al caso de la babysitter (Stree, 1966, p. 148 y ss.) para hacer ver que la "relación de garantía" no depende del contrato, pues si por ejemplo éste fuera nulo, igualmente aquélla se encontraría obligada tanto a la protección como a la vigilancia del niño, en la medida en que hubiera asumido fácticamente tal función. Crítico también es Herzberg (1972, p. 212), aunque después sostiene, en contra de Stree (1966), que la asunción fáctica funda una posición de garante solamente cuando se trata de la vigilancia de una fuente de peligro, mas no de una función de protección (Herzberg, 1972, p. 348 y ss.). Según Stree (1966, p. 154), lo decisivo tampoco es la situación de confianza que se genera por la asunción, pues no es posible extraer de ninguna parte del ordenamiento jurídico que aquélla funde un deber especial. Lo determinante sería el comportamiento del sujeto que confía. De acuerdo a este razonamiento, la asunción de una labor de protección o de vigilancia, puede producir el efecto de que el propio titular del bien jurídico protegido incurra en una conducta peligrosa, o que otros sujetos se inhiban de realizar actividades de vigilancia del peligro o de protección del bien jurídico. En una expresión sintética, el criterio determinante para la posición de garante fundada en la asunción sería la producción de un "momento de peligro" (Stree, 1966).

La posición de garante, empero, es un elemento normativo en cuya virtud el sujeto resulta obligado -según la así llamada teoría de las funciones- a la vigilancia de una fuente de peligro determinada o a la protección de un sujeto determinado frente a una situación también de peligro. Es decir, el elemento común es de carácter normativo y radica precisamente en el deber de evitar la realización del peligro. Bajo este supuesto, entonces, resulta al menos paradójico exigir, como lo hace Stree (1966), entre otros (entre nosotros, por ejemplo, Politoff Lifschitz, 1997, p. 319 y ss.), que derive un peligro a partir de la asunción previa del sujeto para luego fundar la posición de garantía cuyo contenido obliga justamente a lo contrario, esto es, a su evitación. Tal exigencia, implica supeditar la vigencia de la obligación de evitar la realización del peligro a la condición de que el propio sujeto haya creado previamente el mismo peligro.

Se trata aquella de una condición que lleva a la misma paradoja en la cual incurrió la teoría del principio de la actividad previa formulada por Merkel (1867, p. 79 y ss.), en la segunda mitad del siglo 19. Como en esa época se partía mayoritariamente de la premisa que la omisión por sí misma no podía ser causal de la lesión al círculo 
de intereses protegidos, entonces se buscaba reconducir dicha causalidad a una acción previa del sujeto - de ahí el nombre del principio-. La omisión de la acción impeditiva, era un componente negativo en la cadena causal gatillada por la acción previa del sujeto. Por decirlo en términos metafóricos, dado que la omisión misma en principio no era causal del daño, sí podía no obstante serlo en la medida en que ella fuera parte de algo así como una gran acción previa indirectamente causal del mismo, de modo tal que así pudiera castigarse la omisión al mismo título que la comisión. Una reformulación moderna y bastante sofisticada del principio de la actividad previa, puede encontrarse en Welp (1968, p. 164 y ss).

Pero, desde esa época ha corrido mucha agua bajo el puente. Entre otras cosas, la premisa de la ausencia de causalidad en la omisión -no sobra recordarlo: nunca aceptada por la jurisprudencia alemana de la época- ha sido sometida a revisión por la propia doctrina (ya desde Engisch (1931, p. 29 y ss.). La omisión ha recuperado su sitial al lado de la acción -y no en oposición a ésta, como sostenía Radbruch (1967, p. 137 y ss.)-, tal como lo reconoce, por lo demás, nada menos que el propio Código penal (1874) que define: "Es delito toda acción u omisión voluntaria penada por la ley" (art. 1). De este modo, entonces, la omisión impropia ya no supone su enrevesada reconstrucción a partir de las características de una acción previa causal del daño -en la versión del principio de la actividad previa-, o de una conducta también previa generadora del peligro para el bien jurídico protegido -en la reformulación del principio de garantía-. Si ahora se opta por tomar en serio a la omisión impropia como tal, entonces esta supone como requisito simplemente la existencia previa de un deber jurídico de evitación.

En este último sentido, y es aquí donde se presenta otro problema con el planteamiento de Stree (1966), exigir para el surgimiento de la posición de garante cuyo contenido obliga a la evitación del peligro, que como consecuencia fáctica de la asunción se haya generado previamente un peligro, ya sea en la forma de impulsar una conducta peligrosa de la propia víctima o por la vía de desactivar o inhibir medidas de resguardo que un tercero habría de adoptar, es incompatible con la antes mencionada premisa de lógica deóntica, aún en su versión reformulada. Desde luego, el deber de garante, que se dirige a la evitación del peligro, no puede surgir meramente de la circunstancia puramente fáctica de la generación previa del mismo peligro. Pero tampoco puede tal deber surgir de la conjunción de los elementos de la asunción y la generación previa del peligro, en la medida en que ambos se comprendan a su vez en términos fácticos. La eventual confianza de la víctima o del tercero en el efectivo cumplimiento de la labor de vigilancia o de protección antes asumida por el sujeto, como lo advierte el propio Stree, no le agrega nada más que un dato también fáctico. El conjunto de premisas del cual deriva la obligación de garantía, empero, ha de contener al menos un elemento normativo. 
No obstante, y a contrapelo de dicha premisa, Stree (1966, p. 159 y ss.) parece creer en la "fuerza normativa de lo fáctico". Pues sostiene que el inicio y el fin de la "relación de garantía" se rigen por los efectos de la asunción fáctica. Tomada en serio esta tesis, implicaría que la labor de vigilancia o de protección debe extenderse por todo el tiempo de duración del "momento de peligro", cuestión que depende de circunstancias a veces muy azarosas. En definitiva, se trata de un planteamiento teórico orientado materialmente, que quizás puede conducir a una solución del caso particular en algún sentido justa, pero a costa de un alto nivel de incerteza jurídica.

Recientemente, Pawlik (2012) acude a una variante moderna del caso del "nadador intrépido" (p. 185) y sostiene que quien mediante su promesa de prestar apoyo "envalentona" a un nadador inseguro para atreverse ir de la parte baja a la honda de la piscina, "debe poner el hombro, si el otro pierde sus fuerzas" (Pawlik, 2012, p. 185). El creador de la declaración debe, por fuerza del "mandato de respeto", compensar mediante su actividad el déficit de protección originado por él mismo. $Y$ agrega: aquí rige la "prohibición del comportamiento autocontradictorio" (Pawlik, 2012, p. 185). Es decir, según este planteamiento, la promesa genera una obligación jurídica si concurren dos elementos. Una circunstancia fáctica derivada del déficit de protección generado por el promitente. $Y$ un elemento de carácter normativo derivado del mandato general de respeto, i.e., "...sé una persona y respeta a los otros como personas" (Hegel, 1970, § 36).

La formulación del elemento fáctico, empero, presupone que el promitente antes confiere protección. Sólo bajo ese supuesto puede hablarse luego de un déficit de protección no compensado. De este modo, resta aún por aclarar el origen y la fuente de tal protección previamente conferida. Pero, en verdad, es el propio nadador intrépido quien decide ir a la parte honda de la piscina, i.e., se expone al riesgo. Por su parte, el elemento normativo se deriva del mandato general dirigido a todo ciudadano de comportarse como persona y de respetar al otro como tal, es decir, una reformulación positiva del neaminem laedere. Tal mandato general subyace a todas las normas de comportamiento protegidas jurídico-penalmente, de modo que es importante tener presente que, en esa medida, el razonamiento citado responde a una construcción netamente jurídico-penal. En este sentido, la "prohibición del comportamiento internamente contradictorio" parece ser una manifestación concreta del mandato general previamente enunciado, pues una persona que se contradice a sí misma no se comporta como tal. No sería indicado entender tal prohibición ni en un sentido moral -deber de decir verdad-, ni tampoco en un sentido netamente lógico -principio de no contradicción.

\subsection{Planteamiento}

Quizás sirva comparar dos casos planteados por Traeger (1913, p. 87), en tanto ambos se sitúan justo en el límite conceptual entre el deber general de auxilio y el 
deber jurídico especial, requisito este segundo de la responsabilidad por omisión impropia. O dicho en términos más actuales, en la frontera entre solidaridad y libertad (cfr. Rojas Araya, 2018, p. 683 y ss., con mayores referencias). Pues bien, un caso es aquel del caminante que se encuentra en despoblado con una persona que ha sufrido una caída y promete enviarle ayuda, pero luego en el camino omite el auxilio bajo la esperanza de que otro sujeto quizás le preste ayuda. Si se observa atentamente el caso, se trata justo de la situación fáctica del tipo general de omisión de socorro (Código Penal, 1874, art. 494, no. 14), con la diferencia que el sujeto emite adicionalmente una promesa de auxilio. La promesa, en ese caso, no es más que la declaración explícita de la voluntad de cumplir la obligación general de auxilio, que subyace al tipo de omisión de socorro (Herzberg, 1972, p. 354). Materialmente, tal declaración deja incólume el mismo deber general.

El otro caso, es aquel del médico que después de un accidente de trenes comienza a realizar una operación absolutamente necesaria a una víctima inconsciente, y luego no la sutura. Según Traeger (1913, pp. 95 y 96), en tal caso, en verdad, rigen los preceptos del Derecho civil sobre "agencia oficiosa", por lo que el médico se encuentra obligado a concluir la operación. Aquí es posible observar dos diferencias con el caso precedente, una fáctica y otra normativa. La fáctica radica en que el médico ya comienza efectivamente el curso salvador, esto es, realiza actos positivamente dirigidos a evitar la realización del peligro previamente existente para la vida y la salud de la víctima del accidente de trenes -no genera por ello un "momento de peligro" -. Este grupo de casos se ha discutido en la doctrina bajo el acápite de la interrupción de un curso salvador propio ("omisión por comisión"), ver; Gimbernat Ordeig (2013, p. 432 y ss.); Silva Sánchez (2003)-. La diferencia normativa, por su parte, consiste en que la realización de estos actos positivos adquiere un significado ante las normas del Derecho civil -no se trata meramente de la "fuerza normativa de lo fáctico"-. Rigen los preceptos sobre "agencia oficiosa", instituto que en tanto "cuasicontrato" no es un contrato y, por ende, se somete a las reglas del Código civil (2000) -de la ley (Stitchkin Branover, 1950, p. 104 y ss)-.

Según estas reglas, el beneficiado por los actos materiales tiene la obligación de compensar al "agente oficioso", en el caso de que la actividad realizada efectivamente le haya reportado utilidad -de lo contrario, habría un enriquecimiento sin causa-. En cambio, si dicha actividad le ha perjudicado, el "agente oficioso" debe indemnizar los perjuicios provocados -conforme a las reglas sobre responsabilidad extracontractual-. En este escenario, y volviendo al caso ejemplar, la víctima ahora doblemente perjudicada -una vez por el accidente y una segunda vez por obra del "agente oficioso"- tiene el derecho a exigir la indemnización de perjuicios. En el momento mismo en que el médico comienza a realizar los actos positivos, entonces, la víctima tiene el derecho a exigir del médico la evitación del resultado y, si finalmente la "agencia oficiosa" le presta efectivamente un servicio, tiene la obligación de compensar al médico. Son reglas de orden legal, entonces, las que fundan derechos y 
obligaciones correlativas en esa situación fáctica. La fuente del deber jurídico especial aquí es la propia ley, no el contrato.

Sin embargo, pareciera que las reglas sobre "agencia oficiosa" tuviesen un alcance puramente patrimonial. Ello depende, no obstante, del alcance que se le pueda dar a la expresión "gestión de negocios". Stitchkin Branover (1950), el destacado civilista chileno, interpreta dicha expresión en un sentido abarcador de toda prestación de servicios que, de mediar consentimiento, daría lugar a un contrato de prestación de servicios, tal "como el médico que atiende a un accidentado en la calle, el albañil que repara una pared próxima a desplomarse, etc." (Stitchkin Branover, 1950, pp. 109 y 110). Pues bien, el ejemplo que menciona del médico que atiende a un accidentado en la vía pública, corresponde exactamente al caso planteado por Traeger (1913).

En conclusión, un deber jurídico especial -"una obligación de garantía"- no surge de la mera asunción de una labor de protección o de vigilancia. Tampoco la promesa unilateral de prestar ayuda por sí misma, puede fundar tal deber. Por consiguiente, este deber sólo puede extraerse de las fuentes formales de la ley o del contrato. Esta restricción tiene bastante sentido, pues ambas fuentes del deber tienen en común que son heterónomas frente al sujeto. Esto es, luego de formado el contrato, el sujeto ya no puede desvincularse unilateralmente de las obligaciones surgidas del mismo. Y esta vinculación externa es la característica propia de la ley como fuente del deber. En este sentido, lo que tienen en común ambas fuentes radica justamente en aquella característica -su heteronomía-, que permite distinguir un deber jurídico de uno moral.

La restricción precedente rige de modo general, a menos que las reglas del ordenamiento jurídico impongan el deber de concluir el curso salvador ya iniciado frente a la situación de peligro y, correlativamente, pueda así fundarse un derecho de la víctima a exigir de ese sujeto dicho cumplimiento. Esto último sucede, cuando resultan aplicables las reglas sobre "agencia oficiosa". Por ende, en este caso el deber jurídico especial de evitación no surge de la asunción fáctica ni de la promesa, sino que deriva de estas reglas del Derecho civil -su fuente es entonces la ley-.

\section{Teoría reformulada del deber jurídico e injerencia}

\subsection{El problema}

La otra cuestión que deja pendiente el postulado regreso a una teoría reformulada del deber jurídico, es aquella que surge del grupo de casos discutido bajo la categoría de la injerencia. Si bien esta siempre fue reconocida como una fuente del deber jurídico junto a la ley y al contrato por la jurisprudencia alemana, en la época 
de formulación de esa teoría, el problema que ella plantea atañe a las dificultades de calificar esta fuente de formal.

A primera vista, la injerencia no tiene nada en común ni con la ley ni con el contrato. Pareciera que en este grupo de casos el origen del deber jurídico fuera de carácter puramente fáctico y material. De ahí que para los planteamientos con tal orientación la injerencia no signifique un problema -ni para el principio de la actividad previa ni para la teoría del principio de garantía-. Por el contrario, tales planteamientos buscan generalizar el criterio del peligro característico de la injerencia y, de ese modo, redefinir las otras fuentes del deber- de alguna manera, materializan las fuentes formales del deber jurídico (así, por ejemplo, Gimbernat Ordeig, 2013)-. Es decir, convierten un caso excepcional, que requiere de justificación propia, en un criterio general.

Pero, si se mantiene la exigencia de que el deber jurídico especial surja de una fuente formal, i.e., reconocida por el ordenamiento jurídico positivo, entonces la injerencia plantea un problema. Y éste radica en que su aceptación como fuente del deber jurídico implicaría reconocer que éste puede emanar de una situación puramente fáctica, cual es, aquella en la que la acción previa del sujeto causa la situación de peligro, a cuya evitación luego el mismo sujeto se encontraría obligado jurídicamente.

\subsection{Un caso de la jurisprudencia nacional}

Sin embargo, y si se observa bien, la constelación de la injerencia no es puramente fáctica, sino que involucra un elemento normativo. Para identificarlo, puede ser útil revisar el siguiente caso de la jurisprudencia nacional, resuelto por la Corte de Apelaciones de Chillán (Ministerio Público c/ Sebastián Ignacio Palacios Monroi, 2011). El caso empieza, cuando tres amigos salen de excursión al sector de "Shangrilá" en las cercanías de dicha ciudad -ahora capital regional-, y después se pierden. Aproximadamente a las 19:30 horas suben a la cima de un pequeño monte con un borde cortado a pique de una altura de doce metros, donde se produce una discusión entre dos de los amigos. En ese momento, el tercero empuja a uno de ellos, quien cae desde el pique del monte entre las rocas y la nieve. Enseguida los amigos dejan abandonada a la víctima, la que posteriormente es encontrada en estado grave por lugareños.

Pues bien, la pregunta que surge en el caso concierne a si, comparativamente, el sujeto que empuja a la víctima y los lugareños, frente a las normas del ordenamiento jurídico positivo, tienen el mismo deber. Por cierto, su cumplimiento adquiere sentido frente a la situación de peligro para la salud y la vida de la víctima, que para ella es objetivamente la misma. Sin embargo, frente a esta situación fáctica, los lugareños se ubican exactamente en la posición descrita como presupuesto del tipo de omisión de socorro del Código Penal (1874 art. 494, no. 14), cuyo fundamento 
radica en un deber general de auxilio. En cambio, el sujeto que empuja a la víctima ha causado con su acción dicha situación de peligro.

Se observa, entonces, una diferencia que surge por la circunstancia de que el sujeto ha causado el peligro. La causalidad, empero, es un elemento netamente descriptivo, de modo que por sí misma no introduce una diferencia normativa. Es necesario captar la injerencia en su significado normativo, este es el punto de partida de Dopico Gómez-Aller (2006, p. 740 y ss.), quien correctamente sostiene que la injerencia debe entenderse en el sentido de interferencia en la esfera de derechos ajena; posteriormente, Dopico Gómez-Aller (2006, p. 767 y ss.), en base a lo que denomina el "principio de gestión", distingue la omisión de aseguramiento ("omiso aseguramiento") de la simple omisión de salvamento ("omiso salvamento"), para luego sostener que solamente aquella omisión de rescate derivada de una previa omisión de aseguramiento sería equivalente a la comisión, mientras que la mera omisión de salvamento por la simple no revocación de consecuencias frente al accidente de la víctima, no lo sería; luego Dopico Gómez-Aller (2006, p. 785 y ss.), recurre a la idea de "usurpación", categoría que supone una gestión "prolongada" de la esfera ajena de bienes como presupuesto de esa identidad estructural. En este planteamiento, llama la atención la fuerte "patrimonialización" de las categorías tradicionales de la omisión impropia, pues se gestiona el patrimonio propio o ajeno y se usurpa un bien inmueble ajeno. El uso de estas categorías patrimoniales, se explica porque así se busca desarrollar la "idea general de dominio" como fundamento común de la omisión impropia, acuñada en su época por Schünemann (2009, p. 275 y ss.). Sin embargo, la aplicación de estas categorías a casos concretos, en definitiva, se traduce en la exigencia de un mayor hacer previo, por ejemplo, en el caso mencionado por Dopico Gómez-Aller (2006, p. 793), en que un conductor atropella y lesiona a una niña, dejándola sobre la calzada con heridas que hubiesen podido curarse de haberla llevado al hospital; horas después, vuelve al lugar del accidente y recoge a la niña inconsciente llevándosela a un garaje, donde la tuvo tirada en el suelo, sólo abrigada con papeles y plásticos, durante diez días; la muerte se produjo como consecuencia de las heridas y una neumonía. De acuerdo con el planteamiento teórico señalado, no basta la injerencia, sino que la posición de garante surge recién cuando, después de volver al lugar del accidente, "sustrae" a la niña de medios de protección. Esto es, conforme a dicho planteamiento, no basta el hacer precedente, sino que es necesario un mayor hacer precedente que implique la "gestión de la esfera ajena" o la "usurpación" de medios de protección de la víctima, es decir, una normativización del principio de la actividad previa, que en esa medida se expone a las mismas críticas que se pueden formular a este último. El problema de esta tesis radica en que, junto con exigir una acción previa adicional a la injerencia misma, introduce un filtro cuantitativo y gradual, sin que sea posible fijar de modo general en qué momento surge la posición de garante, en el ejemplo, ¿ya cuando la recoge del lugar o recién cuando la tiene en el garaje? El mismo problema se plantea, y más aún, con la variable temporal. Recien- 
temente, Jakobs $(2012$, p. 37) concibe la injerencia en el sentido de una interferencia en el círculo ajeno de derechos, es decir, de una ampliación de la propia esfera de organización de tal forma perjudicial a la víctima, que ésta adquiere la pretensión de mantenerse indemne frente a las consecuencias que amenazan realizarse. No habla de un derecho.

Esa pretensión de la víctima de la injerencia, esto es, de la situación de peligro causada por el sujeto, alcanza el status de derecho en la medida en que correlativamente exista un deber jurídico de evitación. Un deber jurídico especial, por su parte, presupone su reconocimiento formal. Pues bien, fuera de los casos en que este deber no es más que la concreción de un deber jurídico de aseguramiento de una determinada fuente de peligro, surgido a su vez de una ley extrapenal o de un contrato, normalmente en los casos de injerencia, como en el ejemplo, no existe una ley ni tampoco un contrato que funde previamente una relación jurídica especial entre el sujeto y la víctima de la situación de peligro.

Aparentemente, en el caso ejemplar, la relación jurídica entre el sujeto y la víctima sería de la misma clase que la existente entre ésta y los lugareños. Sin embargo, la acción del sujeto no agota su significado en la circunstancia de haber causado la situación de peligro para la víctima. Además, dicha acción tiene el significado normativo de interferir en el círculo de derechos de la víctima, por lo que su realización, en la medida en que además infringe la norma de comportamiento respectiva, obliga luego a restablecer la intangibilidad del círculo de derechos previamente afectado. Es el carácter antijurídico de la acción previa, entonces, el que convierte la norma prohibitiva en un mandato de realizar la acción impeditiva. En este sentido, el deber jurídico especial de evitación surge indirectamente de la propia ley penal. Esta funge, por consiguiente, solamente en el caso de la injerencia como fuente formal de tal clase de deber. En esa línea, Stein (1999), quien deriva la "posición de garante" de las normas prohibitivas de comisión, procedimiento que sería correcto, pues a tales normas subyace la valoración de que el interés del portador del bien jurídico, de no verse expuesto a los peligros que surgen de las acciones respectivamente prohibidas, prima por sobre el interés de libertad del destinatario de la norma; cuando el peligro resulta de una acción realizada en contravención a una prohibición, a cuya evitación servía la prohibición de la acción, entonces se le impone al portador del bien jurídico una carga que, conforme a las valoraciones subyacentes a tales prohibiciones de acción, no debe soportar:

...quien infringe un deber de conducta, ejerce una libertad de acción que el ordenamiento jurídico no le ha concedido y obtiene así una ventaja que jurídicamente no le corresponde; la carga reforzada con un deber de garante puede legitimarse con la idea de justicia como igualdad. (Stein, 1999, p. 271) 


\subsection{Compatibilidad de la injerencia con la premisa de lógica deóntica}

Es decir, la norma de comportamiento subyacente a la ley penal, puede formularse tanto en los términos de una prohibición como de un mandato de acción. En ambas formas, el precepto normativo expresa deberes (Weinberger, 1988, p. 61). En el caso de la injerencia, el sujeto interfiere en el círculo de derechos de la víctima mediante la realización de su acción previa que infringe la norma de comportamiento en la forma de la prohibición, por lo que esta misma norma se vuelve operativa ahora en la forma de un mandato de acción, esto es, un deber de evitación. La víctima, por su parte, tiene derecho a exigir de ese sujeto infractor el cumplimiento del deber. No se trata, entonces, de un mero deber general de auxilio, sino que de un deber jurídico especial de evitación.

En esa medida, tal clase de deber no surge meramente del hacer precedente que causa la situación de peligro. Si esto fuera así, esta derivación sería incompatible con la premisa de lógica deóntica antes enunciada. Aplicada esta premisa en su versión reformulada, ella exige que el deber surja de un conjunto de elementos tanto fácticos como normativos. Mas el elemento normativo que integra el conjunto de premisas del cual surge el deber, ha de consistir a su vez en el mismo imperativo que luego se expresa en el deber, de tal modo que éste, en definitiva, no sea más que la explicitación de una premisa normativa ya inserta en dicho conjunto lógicamente previo (Hare, 1972). Pues bien, vista la injerencia a la luz de esta premisa así reformulada, ella satisface sus exigencias en la medida en que la acción previa del sujeto vulnere la norma prohibitiva subyacente al tipo cuya aplicación se ventila en el caso concreto. Dicha norma, contiene el imperativo de no realizar una conducta apta para lesionar el bien jurídico protegido por ella. Si la acción previa del sujeto al causar la situación de peligro vulnera esa norma prohibitiva, dicho en los términos de la teoría de la imputación objetiva, crea un riesgo jurídicamente desaprobado, el deber de evitación del resultado no es más que una concreción de la misma norma.

Este razonamiento presupone, eso sí, que la norma de comportamiento de un delito de resultado prohíbe ya la creación de un riesgo para el bien jurídico protegido, premisa de la cual parte la teoría de la imputación objetiva con su distinción gruesa entre riesgo prohibido y realización del resultado. Es decir, la creación jurídicamente desaprobada del riesgo, o en su formulación equivalente, la realización de una acción prohibida por la norma de comportamiento, funda luego el deber de evitar la realización del peligro, cuya ocurrencia constituye un presupuesto de aplicación de la norma de sanción correspondiente.

Lo dicho implica que la injerencia funda un deber jurídico especial de evitación solamente en la medida en que el hacer precedente, que causa la situación de peligro, infrinja además una norma de comportamiento cuyo fin abarca la protección del bien jurídico amenazado. Esto se traduce, en la exigencia de contrariedad a deber 
o antijuridicidad de la acción previa para los efectos de fundar jurídicamente el deber de evitación, cuyo incumplimiento configura luego el injusto de un delito impropio de omisión -exigen tal requisito, pero por las más diversas consideraciones: Gallas (1989, p. 90 y s.); Rudolphi (1966, p. 157 y ss., 183 y ss.); Stree ${ }^{10}(1983$, p. 398 y ss.); y Dencker (1993, p. 171 y s., 176)-. En consecuencia, no surge tal deber del hacer precedente, si el peligro que resulta de la acción previa se mantiene dentro del riesgo permitido o se encuentra amparado por una causa de justificación (de otra opinión; Traeger, 1913, p. 98 y ss.; Welp, 1968, p. 209 y ss.; Freund, 1992, p. 180 y ss.; Jakobs, 2012, p. 37 y s.; titubeante, Herzberg, 1972, p. 282 y ss., 306 y ss.;; Dopico GómezAller ${ }^{11}, 2006$, p. 799 y ss.). En estos últimos casos, subsiste el deber general de auxilio, cuya infracción, empero, se ve agravada por la circunstancia de haber causado la situación de peligro para la víctima. Dado que nuestro sistema no cuenta con una "figura agravada de omisión de socorro", al respecto Silva Sánchez (2003, p. 428 y ss.) ("omisiones de gravedad intermedia" u "omisiones puras de garante", esta última denominación, empero, es desafortunada, pues supone la "posición de garante" y, en esa medida, ya deja de ser "pura"), es necesario partir de la pena contemplada por el correspondiente delito de resultado y luego constatar la ausencia de uno de los requisitos de la eximente de responsabilidad criminal del Código Penal (1874, art. 10, no. 8), puesto que su configuración exige la realización de un acto lícito que causa un mal por mero accidente. Y la hipótesis fáctica en comento, supone que el resultado ("el mal") ha sido causado indirectamente por un acto lícito, pero no por accidente, pues, en definitiva, el resultado es imputable a la infracción del deber general de auxilio mediante omisión. En esa medida, resultaría aplicable a este caso la eximente incompleta del Código Penal (1874, art. 11, no. 1), en relación con la regla del art. 73 del mismo cuerpo legal (1874).

A modo de cierre, es importante recordar que aquí se encuentra en juego nada más que la configuración de un requisito básico en la estructura típica del delito impropio de omisión. Si se regresa a una versión reformulada de la teoría del deber jurídico, tal requisito consiste en la existencia formal de este deber. Con su verificación, entonces, se configura solamente un presupuesto del tipo de tal clase de delito. Todavía es menester analizar la configuración de los otros requisitos del tipo, como el nexo de causalidad y los criterios de imputación objetiva. Recién una vez que se ha concluido este análisis del tipo objetivo, corresponde preguntarse luego por la imputación a dolo o solamente a imprudencia.

Tal estructura típica, también debe configurarse para fundar responsabilidad por omisión en los casos de injerencia. Por ende, también en estos casos debe separarse cuidadosamente, por una parte, el análisis de los requisitos exigidos para que el deber jurídico de evitación surja del hacer precedente y, por otra, la verificación de

\footnotetext{
${ }^{10}$ Requisito de la conexión de infracción de deber "junto con el peligro "cercano o próximo"

${ }^{11}$ Para este autor lo decisivo no sería la antijuridicidad de la acción previa, sino que la afectación de la autonomía ajena mediante su realización.
} 
los demás elementos objetivos y subjetivos del tipo de omisión impropia. Sólo así puede uno darse cuenta, que la pregunta por los requisitos exigidos para que el hacer precedente pueda fundar el deber jurídico es de orden exclusivamente objetivo esto es, basta una acción causal del peligro o es necesaria la concurrencia de requisitos normativos adicionales- y que, por ende, en esta sede del análisis nada tienen que hacer ni el dolo ni la imprudencia. En cambio, y una vez que se ha constatado la existencia de tal deber por el cumplimiento de sus requisitos propios, corresponde recién preguntarse, luego de verificar la infracción del deber mediante omisión y los otros requisitos objetivos del tipo, si hay dolo o solamente culpa. De esta manera, se pone de manifiesto que también en los casos de injerencia, el objeto al cual se encuentra referido el dolo es el mismo que en los demás casos de omisión impropia, esto es, la situación de peligro frente a la cual se incumple el deber jurídico de evitación. Si resulta que en el caso concreto, además, ocurre que la acción previa causal del peligro se ha realizado dolosa o culposamente, entonces en ese caso se presenta un problema concursal, que precisamente supone la concurrencia de al menos dos delitos. Un enfoque como el seguido por Izquierdo Sánchez (2006, p. 331 y s., 337 y s., 341 y s.), confunde el análisis de los requisitos exigidos para que el hacer precedente funde una posición de garantía con los problemas concursales que eventualmente pueden presentarse en el caso concreto; hasta donde se alcanza ver, nunca se ha exigido que el hacer precedente constituya un delito culposo o doloso para que pueda surgir tal clase de deber jurídico y, si así se hiciera, sería exigir demasiado, esto es, que el hecho precedente sea típico, antijurídico y culpable; basta que la acción previa sea causal del peligro y que además ella sea antijurídica -nada más; por la misma razón, no puede extraerse ninguna conclusión acerca de los requisitos de la injerencia como fuente del deber jurídico a partir de preceptos que o bien resuelven expresamente problemas concursales, como en los ejemplos del secuestro calificado (Código Penal, 1874, art. 141, inc. 5, y art. 142, inc. 2) o recientemente en la Ley de Tránsito (Decreto con Fuerza de Ley $N^{\circ} 1,2009$, art. 195, inc. 4), o bien contemplan figuras calificadas de un delito de peligro, como en el mismo Decreto con Fuerza de Ley $\mathrm{N}^{\circ} 1$, (2009, art. 195, inc. 3) o en los clásicos ejemplos del delito de incendio (Código Penal, 1874, art. 474) o de abandono de personas (Código Penal, 1874, arts. 348, 351 y 352 ). Pero esto último, es harina de otro costal.

\section{Conclusiones}

El regreso a la teoría formal del deber jurídico, más reformulada modernamente con los criterios desarrollados por la teoría de la imputación objetiva, permite acuñar un modelo de análisis mejor estructurado del tipo de la omisión impropia. Tal modelo exige separar claramente, por un lado, la pregunta por la existencia formal de un deber jurídico especial de evitación y, por el otro, el análisis de los demás elementos objetivos y subjetivos de dicho tipo. 
La estructura típica del delito impropio de omisión es siempre la misma. La configuración de esta estructura supone antes la existencia formal de un deber jurídico especial.

La ley y el contrato, tienen en común de que se trata de fuentes heterónomas del deber jurídico. La heteronomía, precisamente, distingue al deber jurídico del moral.

Ese elemento común a la ley y al contrato de la heteronomía, no concurre en la asunción previa de una labor de protección o de vigilancia. Afirmar que de la realización de tal actividad protectora o vigilante pueda surgir un deber jurídico de evitación, implicaría sostener que para los efectos de la responsabilidad penal por omisión impropia también un sujeto puede obligarse jurídicamente a sí mismo autovinculación sin contrato ni ley-.

La asunción previa de una labor de protección o de vigilancia como tal, no es fuente del deber jurídico de evitación. Sin perjuicio de lo anterior, si el sujeto, frente a la situación de peligro desencadenada, comienza ya a realizar la acción impeditiva, se encuentra luego obligado a terminarla correctamente. Las reglas sobre agencia oficiosa, cuya fuente es la ley, le obligan jurídicamente a ello.

En la constelación de la injerencia, es la causación antijurídica de la situación de peligro la que convierte la norma de prohibición en un mandato de realización de la acción impeditiva. El destinatario general de la norma de prohibición, se circunscribe luego al sujeto que causó antijurídicamente la situación de peligro, de modo tal que la víctima adquiere el derecho a exigir de ese sujeto la realización de dicha acción.

$\mathrm{Si}$, por el contrario, es el sujeto quien tenía derecho a realizar la acción previa que causó la situación de peligro, entonces de esta circunstancia fáctica no surge un deber jurídico especial de evitación. En este caso, la víctima se encuentra amparada por un deber general de auxilio, cuyo incumplimiento por parte del sujeto, sin embargo, se ve agravado por la causación previa de la situación de peligro.

\section{Reconocimientos}

Trabajo escrito en el marco del proyecto FODECYT (Regular) N 1150178 sobre "Líneas básicas de una dogmática de los delitos propios de omisión: una aproximación a los deberes de solidaridad y al significado de su infracción", cuyo investigador responsable es el autor; coinvestigadora en el proyecto es la Dra. María Soledad Krause; agradecimientos al ayudante de investigación Mg. Claudio Quintana. 


\section{Referencias Bibliográficas}

Aubtreibungsversuch. Beihilfe, I 339/21 (Reichsgericht 6 de octubre de 1921). Entscheidungen des Reichsgerichts in Strafsachen, 1922 (56), 168-171

Blei, H. (1966). Garantenpflichtbegründung beim unechten unterlassen. En F. Geerds y W. Naucke (Eds.), Beiträge zur gesamten Strafrechtswissenschaft: Festschrift fur Hellmuth Mayer zum 70. Geburtstag am 1. Mai 1965 (pp. 110-143). Berlin: Duncker \& Humblot.

Brandstiftung durch Unterlassung, II 419/30 (Reichsgericht 16 de junio de 1930). Entscheidungen des Reichsgerichts in Strafsachen, 1931 (64), 273-279.

Código Civil. Diario Oficial de la República de Chile, Santiago, Chile, 30 de mayo de 2000. Recuperado de http://bcn.cl/2f6t3

Código Penal. Diario Oficial de la República de Chile, Santiago, Chile, 12 de noviembre de 1874. Recuperado de http://bcn.cl/2f6m7

Contesse Singh, J. (2017). La omisión impropia como hecho punible. Acerca de la incorporación de una regla general de punibilidad de los así llamados 'delitos de omisión impropia' en el anteproyecto de Nuevo Código Penal. En K. Ambos, E. Malarino, J. P. Matus Acuña, G. Urquizo y J. Winter Etcheberry (Coords.). Reformas Penales (pp. 11-49). Santiago: DER.

von Bar, C. (1988). Entwicklungen und Entwicklungstendenzen im Recht der Verkehr(sicherungs)pflichten. Juristische Schulung, (3), 169-174.

Decreto con Fuerza de Ley $N^{\circ} 1$. Fija texto refundido, coordinado y sistematizado de la Ley de Tránsito. Diario Oficial de la República de Chile, Santiago, Chile, 29 de octubre de 2009. Recuperado de http://bcn.cl/2f8iq

Dencker, F. (1993). Ingerenz: die defizitäre Tathandlung. En W. Küper y J. Welp (Eds.), Beiträge zur Rechtswissenschaft: Festschrift für Walter Stree und Johannes Wessels zum 70. Geburtstag. (pp. 159-181) Heidelberg: C.F. Müller.

Dopico Gómez-Aller, J. (2006). Omisión e injerencia en derecho penal. Valencia: Tirant lo Blanch.

Engisch, K. (1931). Die Kausalität als Merkmal der strafrechtlichen Tatbestände. Tübingen: Mohr Siebeck.

von Feuerbach, P. J. A. (1847). Lehrbuch des gemeinen in Deutschland gültigen peinlichen Rechts (14 ed.) Giessen: George Friedrich Heyer's. Recuperado de https://bit.ly/3dQtrQV 
Freund, G. (1992). Erfolgsdelikt und Unterlassen: zu den Legitimationsbedingungen von Schuldspruch und Strafe. Köln: Heymann.

Freund, G. (2017). § 13 Begehen durch Unterlassen. En B. Von Heintschel-Heinegg (Ed.), Münchener kommentar zum Strafgesetzbuch: §§ 1-37 (3a ed., Vol. 1, pp. 566-652). München: C. H. Becks.

Frisch, W. (1988). Tatbestandsmaßßiges Verhalten und Zurechnung des Erfolgs, Heidelberg: C. F. Müller.

Gallas, W. (1989). Studien zum Unterlassungsdelikt. Heidelberg: Decker \& Müller.

Gimbernat Ordeig, E. (2013). Estudios sobre el delito de omisión (2a ed). Buenos Aires: B de F.

Grünewald, A. (2001). Zivilrechtlich begründete Garantenpflichten im Strafrecht?. Berlin: Duncker \& Humblot.

Hare, R. M. (1972). Die Sprache der Moral (P. von Morstein, Trad.). Frankfurt am Main: Suhrkamp.

Hegel, G. W. F. (1970). Grundlinien der Philosophie des Rechts. Frankfurt am Main: Suhrkamp.

Herzberg, R. D. (1972). Die Unterlassung im Strafrecht und das Garantenprinzip, Berlin: De Gruyter. doi: 10.1515/9783110894745

Izquierdo Sánchez, C. (2006). Comisión por omisión: algunas consideraciones sobre la inJerencia como fuente de la posición de garante. Revista chilena de derecho, 33(2), 329-343. doi: 10.4067/S0718-34372006000200007

Jakobs, G. (2012). System der strafrechtlichen Zurechnung. Frankfurt am Main: Westdeutscher.

Kaufmann, A. (1959). Dogmatik der Unterlassungsdelikte. Göttingen: Otto Schwartz \& Co.

Kindhäuser, U. (1989). Gefahrdung als Straftat: rechtstheoretische Untersuchungen zur Dogmatik der abstrakten und konkreten Gefahrdungsdelikte. Frankfurt am Main: V. Klostermann.

Ley $N^{\circ}$ 20.830. Crea el acuerdo de unión civil. Diario Oficial de la República de Chile, Santiago, Chile, 21 de abril de 2015. Recuperado de http://bcn.cl/2gbdj

Mayer, U. (1934). Die besonderen Tatbestandsmerkmale der unechten Unterlassungsdelikte (Tesis doctoral). Ruprecht-Karls-Universität Heidelberg. 
Merkel, A. (1876). Von den Unterlassungsverbrechen, beziehungsweise dem negativen Unrechte, und ihrem Gegensatz, und von dem Verhältniss der ersteren zu den Polizeivergehen. En Kriminalistische Abhandlungen (pp. 76-103). Leipzing: Breitkopf und Härtel. Recuperado de https://bit.ly/2Q9TFWH

Ministerio Público c/ Sebastián Ignacio Palacios Monroi, Rol N 186-2011 (Corte de Apelaciones de Chillán 07 de octubre de 2011). Recuperado de https://app.vlex.com id: 581448674

Morgenstern, H. (1997). Unterlassene Hilfeleistung. Solidarität und Recht. Frankfurt am Main: Peter Lang.

Nagler, J. (1938). Die Problematik der Begehung durch Unterlassung. Der Gerichtssaal, $111,1-121$.

Novoa Monreal, E. (2005). Curso de derecho penal chileno: parte general (3a ed., Vol. 1). Santiago: Jurídica de Chile.

Pawlik, M. (1999). Das unerlaubte Verhalten beim Betrug. Köln: C. Heymanns.

Pawlik, M. (2012). Das Unrecht des Bürgers: Grundlinien der allgemeinen Verbrechenslehre. Tübingen: Mohr Siebeck.

Politoff Lifschitz, S. (1997). Derecho penal (Vol. 1). Santiago: ConoSur.

Puppe, I. (2015). Das System der objektiven Zurechnung. Goltdammer's Archiv für Strafrecht, 162(4), 203-218.

Quintana Román, C. (s. f.). Jurisprudencia chilena sobre delitos de omisión en el período cronológico 1900-2015 (Informe Proyecto FONDECYT N 1150178)

Radbruch, G. (1967). Der Handlungsbegriff in seiner Bedeutung für das Strafrechtssystem: zugleich ein Beitrag zur Lehre von der rechtswissenschaftlichen Systematik. Darmstadt: Wissenschaftliche Buchgesellschaft.

Renzikowski, J. (2002). Die Unterscheidung von primären Verhaltens- und sekundären Sanktionsnormen in der analytischen Rechtstheorie. En D. Doilling y V. Erb (Eds.). Festschrift für Karl Heinz Gössel zum 70. Geburtstag am 16. Oktober 2002 (pp. 3-13). Heidelberg: C.F. Muiller.

Rojas Aguirre, L. E. (2018). Delitos de omisión entre libertad y solidaridad. Política criminal, 13(26), 682-738. doi: 10.4067/S0718-33992018000200682

Roxin, C. (2003). Strafrecht Allgemeiner Teil: besondere Erscheinungsformen der Straftat (Vol. 2). München: C. H. Beck. 
Regreso a una teoría formal del deber jurídico en el ámbito de la omisión impropia

Rudolphi, H. J. (1966). Die Gleichstellungsproblematik der unechten Unterlassungsdelikte und der Gedanke der Ingerenz. Göttingen: O.Schwartz \& Co.

Schöne, W. (1974). Unterlassene Erfolgsabwendungen und Strafgesetz: zur gesetzlichen Regelung "unechter" Unterlassungsdelikte. Köln: Heymanns.

Schünemann, B. (2009). Fundamento y límites de los delitos de omisión impropia: con una aportación a la metodología del derecho penal (J. Cuello Contreras y J. L. Serrano González de Murillo, Trads.). Madrid: Marcial Pons.

Searle, J. R. (1983). Sprechakte (R. Wiggershaus, Trad.). Frankfurt am Maine: Suhrkamp.

Seelmann, K. (1989). Opferinteressen und Handlungsverantwortung in der Garantenpflichtdogmatik. Goltdammer's archiv für strafrecht , 241-256.

Seelmann, K. (1994). Privatrechtlich begründete Garantenpflichten?. En K. Schmidt (Ed.), Vielfalt des Rechts - Einheit der Rechtsordnung? (pp. 85-96). Berlin: Duncker \& Humblot.

Silva Sánchez, J. M. (2003). El delito de omisión (2a ed.). Montevideo: B de F.

Stein, U. (1999). Garantenpflichten aufgrund vorsätzlich-pflichtwidriger Ingerenz. Juristische Rundschau (7), 265-273. doi: 10.1515/juru.1999.1999.7.265

Stitchkin Branover, D. (1950). El mandato civil. Santiago: Jurídica de Chile.

Strafgesetzbuch. 15 de mayo de 1871. Recuperado de https://bit.ly/31WbWZW

Stree, W. (1966). Garantenstellung kraft Übernahme. En F. Geerds y W. Naucke (Eds.), Beiträge zur gesamten Strafrechtswissenschaft: Festschrift fur Hellmuth Mayer zum 70. Geburtstag am 1. Mai 1965 (pp. 145-164). Berlin: Duncker \& Humblot.

Stree, W. (1983). Ingerenzprobleme. En G. Kohlmann (Ed.), Festschrift für Ulrich Klug zum 70. geburtstag. (Vol. 2, pp. 295-404). Köln: Dr. Peter Teubner.

Traeger, L. (1913). Das Problem der Unterlassungsdelikte im Straf- und Zivilrecht. En Philipps-Universität Marburg, Juristische Fakultät (Ed.), Festgaben für Ludwig Enneccerus (pp. 5-126). Marburg: Elwert.

Unfallrente. Vetrug durch Verschweigen der Heilung, IV 1328/12 (Reichsgericht 28 de enero de 1913). Entscheidungen des Reichsgerichts in Strafsachen, 1913(46), 414-417.

Urquieta con Tracción Eléctrica, (Corte Suprema 29 de agosto de 1917). Revista de derecho, jurisprudencia y ciencias Sociales, 1918, 15(2), 131-143.

Weinberger, O. (1988). Norm und institution: Eine einfuhrung in die Theorie des Rechts. Wien: Manz. 
Welp, J. (1968). Vorangegangenes Tun als Grundlage einer Handlungsäquivalenz der Unterlassung. Berlin: Duncker \& Humblot.

Wilenmann von Bernath, J. (2016). Sobre la estructura argumentativa de los delitos de omisión impropia. En C. Cárdenas Aravena y J. Ferdman Niedmann (Coord.), El derecho penal como teoría y como práctica: libro en homenaje a Alfredo Etcheberry Orthusteguy (pp. 275-322). Santiago: Thomson Reuters.

von Wright, G. H. (1979). Norm und handlung: eine logische Untersuchung (G. Meggle y M. Ulkan, Trad.). Königstein im Taunus: Scriptor.

\section{Para citar este artículo bajo Norma APA 6a ed.}

Rojas Aguirre, L. E. (2021). Regreso a una teoría formal del deber jurídico en el ámbito de la omisión impropia. Revista de derecho (Coquimbo. En línea), 28, e4871. https://doi.org/10.22199/issn.0718-9753-2021-0008 